\title{
On Nikolai Vladimirovich Churaev
}

DOI: $10.1134 / \mathrm{S} 1061933 \mathrm{X} 10050017$

This issue was prepared for the 90th Birthday of N.V. Churaev; however, it is actually devoted to his memory because, unfortunately, Nikolai Vladimirovich (hereafter, N.V.) has not lived to see his jubilee, having passed away on February 4, 2010. A great deal has been written on his works, and the obituary has already been published; therefore, although I am his official successor at the journal, I would like to not take an official tone, but rather to share my impressions and memories.

N.V. began working at the Institute of Physical Chemistry, USSR Academy of Sciences, Moscow in 1965 and, since that time, I was able to observe all of his activities. Now, one can hardly imagine that, at that time, the institute was at its maximum occupancy and competition between researchers was very intense. Nevertheless, having obtained security in his job via B.V. Derjaguin's invitation to his department, N.V. soon broke free from the masses and became a leader (since 1967, he had headed the Laboratory of Thin Layers of Liquids), eventually becoming Derjaguin's right hand. N.V. achieved this due to his high working capacity and productivity. Features such as personal devotion (which is so appreciated by chiefs), captation, and doxology were absolutely alien to N.V.; some restraint was always felt in his relations with other people. Given his honesty and modesty, one will understand why N.V. attracted decent people.

In the 1970s and, especially, the 1980s, the international scientific authority of N.V. evolved; he actively participated in foreign publications and international conferences, gradually joining the international elite in colloid science, finally becoming one of its organizers along with B.V. Derjaguin. To some, this would have been the time to consider a career as an academi- cian, i.e., being elected to USSR Academy of Sciences; however, N.V. once and for all closed that door for himself when he said, "I do not play these games." I shall not guess at the reasons for this decision, apparent as they might seem; however, being a person who "played these games," I can confirm that N.V. saved a great deal of time and mental health.

It is impossible to not mention another key person in domestic colloid science with whom N.V. also worked closely, i.e., academician I.V. PetryanovSokolov. After the death of P.A. Rehbinder (whose friend he was), the latter undertook the cause for the Scientific Council on Colloid Chemistry and Physicochemical Mechanics and entreated N.V. to become his assistant. In fact, N.V. headed the Scientific Council, i.e., he managed colloid science on the All-Union scale until 1991, which was a colossal work. I remember the warmth and affection with which PetryanovSokolov treated N.V. In 1989, Petryanov-Sokolov was elected as the editor-in-chief of Colloid Journal. Of course, N.V. became his assistant and, in fact, the editor-in-chief because the academician was not a specialist in colloid chemistry. After I.V. Petryanov passed away in 1996, this position was assigned officially. Thus, we can say that N.V. was at the helm of the Colloid Journal for recent 21 years. This time was the most difficult in domestic science; nevertheless, the impact and international authority of the journal has increased and its portfolio is never empty.

I cherish the memory of N.V. and, from the bottom of my heart, greet the authors and readers of Colloid Journal and wish them new scientific success.

A. I. Rusanov 